\title{
An Experimental Study of Strength of Young Sea Ice
}

\author{
Wilford F. Weeks and Don L. Anderson
}

\begin{abstract}
Values for the strength of sea ice are extremely sparse in the literature, and available values show a wide, unexplained variation. Results of in-place cantilever beam tests presented in this paper show a definite relationship between flexural strength and brine content. Values for Young's modulus are also experimentally determined. It is shown that the bearing capacity of a sea-ice sheet is dependent on the brine content and that thin ice sheets are capable of supporting a large 'super load' beyond the force necessary to form the first crack.
\end{abstract}

Introduction-Detailed studies of the basic physical properties of sea ice are very few. Malmgren's [1927] work still remains the standard reference. In particular, information regarding the strength characteristics of sea ice is noticeably absent. Inasmuch as increased activity in the polar regions during IGY has necessitated the use of unprepared sea-ice surfaces as floating platforms for scientific activity, the bearing strength of sea ice has become an extremely critical problem.

The specific objectives of the present study are: (1) to determine the relations between the flexural strength and Young's modulus of sea ice and such parameters as ice temperature, salinity, and density; (2) to calculate the bearing capacity of young sea ice; and (3) to develop theoretical relations for the analysis of sea-ice strength based on the observed distribution of brine and air pockets so that it will be possible to extend experimentally determined strength curves.

The present study considers only in-place cantilever tests on thin $(<40 \mathrm{~cm})$, newly formed sea ice. This material was chosen since there is a large variation in its brine content and it is thin enough so that a large number of strength tests could be performed in a reasonable amount of time. This was considered necessary since previous work by Petrov [1955] has shown that the results of small sample strength tests on sea ice show a large scatter. Also, these tests duplicate conditions on the warm underside of the ice where the ice initially fails.

The sites of the field tests were North Star Bugt, Thule, Greenland, and Hopedale, Labrador. The tests were performed in areas of homogeneous sheet ice. Testing started as soon as the ice became strong enough to support the weight of the test equipment. Tests were made on this ice sheet at regular intervals during its growth up to a maximum thickness of $40.2 \mathrm{~cm}$. This procedure, however, made it possible to collect only a very small amount of information during the freeze-up period since at any given ice thickness the ice can be tested at only one temperature and salinity. To avoid this difficulty, a number of large ponds (rectangular ice-free areas) were cut in the ice. These ponds were allowed to freeze on different dates so that ice of varying thickness and salt content could be tested during a period of a given air temperature.

The majority of published sea-ice strength tests have been made using small samples that were removed from the ice sheet and allowed to reach equilibrium with the air temperature [Butkovich, 1956; Petrov, 1955; Veinberg, 1940]. This type of testing is not suitable for studying very young sea ice, because when the specimen is removed from the water (1) a large portion of its brine content is lost by drainage; (2) it is often not capable of supporting its own weight; and (3) it is impossible to re-establish the exact in-situ temperature gradient. Also, the results of in-place, cantilever tests show a much smaller scatter than most small-sample tests [Butkovich, 1956]. Therefore all the tests were performed in place in the ice sheet so that the physical properties of the specimen would be identical to those of the over-all sheet.

Flexural strength-The general technique for obtaining the in-place flexural strength of sea ice was used by Neronov [1946] and other Russians, earlier, to measure the flexural strength of lake ice. First a U-shaped channel is cut in the ice sheet with an ice-pond saw. This channel isolates an in-place cantilever ice beam with one end attached to the sheet. Both pull-up and push-down tests were performed on these beams. On the pull-up tests a chain is placed around the end of the ice beam and attached to the end of a wooden lever. A force is then applied by rolling a heavy barrel from the fulcrum to the end of the lever. From the weights and positions of the chains, lever, and barrel at the time the ice beam breaks, the force 
applied to the end of the in-place beam can readily be computed. When the ice was very thin, the force was applied manually, using a dynamometer to measure the force at the end of the ice beam.

The push-down tests were performed using an additional lever that was anchored to the ice sheet. This lever transmitted a downward force to the end of the ice beam. When push-down tests were made on thin ice, a known weight attached to a dynamometer was lowered manually onto the end of the ice beam. In this case the force at the time of failure is simply the known weight minus the dynamometer reading.
The cantilever beam width was kept roughly $\frac{1}{2}$ to 2 times the ice thickness and the length between 3 and 6 times the ice thickness. The average loading rate during the tests was $0.5 \mathrm{~kg} / \mathrm{cm}^{2} \mathrm{sec}$.

After failure the broken segment of the ice beam was immediately removed from the water and three measurements each were made of its length and its height and width at the failure cross section. Three measurements were necessary because of the irregularity of the break. A 7.6-cm diameter vertical core was taken from the sheet in the area of the tests, for the determination of a salinity profile. The ice samples from the core were immediately

TABLE 1 - Results of in-place cantilever beam tests

\begin{tabular}{|c|c|c|c|c|c|c|c|c|c|c|c|c|}
\hline $\begin{array}{l}\text { Test } \\
\text { series }\end{array}$ & Date & $\begin{array}{c}\text { Type of } \\
\text { test } \\
\mathrm{U}=\text { pull } \\
\mathrm{upp} \\
\mathrm{D}=\text { push } \\
\text { down }\end{array}$ & $\begin{array}{l}\text { No. of } \\
\text { tests }\end{array}$ & $\sigma$ & $S \begin{array}{l}S \text { Stan. } \\
\text { dev. }\end{array}$ & $\sigma_{k}$ & $\sigma_{m}$ & Av. sal. & $\begin{array}{c}\text { Aver. ice } \\
\text { temp. }\end{array}$ & $\begin{array}{l}\text { Ice } \\
\text { thick- } \\
\text { ness }\end{array}$ & $\begin{array}{l}\text { Skel. } \\
\text { layer }\end{array}$ & $\begin{array}{l}\text { Ice type } \\
\mathrm{S}=\text { sheet } \\
\mathrm{P}=\text { pond }\end{array}$ \\
\hline & & & & $\mathrm{kg} / \mathrm{cm}^{2}$ & & $\mathrm{~kg} / \mathrm{cm}^{2}$ & $\mathrm{~kg} / \mathrm{cm}^{2}$ & $\%$ & ${ }^{\circ} \mathrm{C}$ & $\mathrm{cm}$ & $\mathrm{cm}$ & \\
\hline 1 & Oct. 29,1956 & U & 2 & 0.72 & 0.14 & 1.19 & 1.40 & 10.7 & -2.4 & 12.7 & 3.6 & $\mathrm{~s}$ \\
\hline 2 & Oct. 31, 1956 & U & 6 & 1.70 & 0.15 & 2.45 & 2.75 & 10.4 & -4.2 & 16.8 & 3.6 & $\mathrm{~S}$ \\
\hline 3 & Nov. 1, 1956 & U & 7 & 1.50 & 0.19 & 2.07 & 2.24 & 8.8 & -3.0 & 18.8 & 3.3 & $\mathrm{~S}$ \\
\hline 4 & Nov. 2, 1956 & $\mathrm{U}$ & 5 & 1.25 & 0.16 & 1.68 & 2.10 & 8.9 & -3.6 & 20.1 & 5.0 & $\mathrm{~S}$ \\
\hline 5 & Nov. 3, 1956 & U & 7 & 1.36 & 0.06 & 1.82 & 2.11 & 8.3 & -2.4 & 20.5 & 4.0 & $\mathrm{~s}$ \\
\hline 6 & Nov. 5, 1956 & U & 3 & 1.05 & 0.07 & 1.34 & 1.47 & 8.1 & -3.4 & 23.6 & 3.6 & $\mathrm{~S}$ \\
\hline 7 & Nov. 6, 1956 & $\mathrm{U}$ & 3 & 1.15 & 0.10 & 1.47 & 1.63 & 8.0 & -4.7 & 24.1 & 3.8 & $\mathrm{~S}$ \\
\hline 8 & Nov. 6,1956 & $\mathrm{U}$ & 7 & 0.86 & 0.04 & 2.16 & 1.91 & 13.0 & -3.5 & 7.6 & 2.5 & $\mathbf{P}$ \\
\hline 9 & Nov. 8,1956 & $\mathrm{U}$ & 7 & 0.92 & 0.08 & 1.66 & 1.62 & 12.3 & -3.0 & 10.9 & 2.7 & $\mathbf{P}$ \\
\hline 10 & Nov. 8,1956 & $\mathrm{U}$ & 2 & 1.11 & 0.28 & 1.66 & 1.82 & 11.0 & -4.2 & 15.5 & 3.4 & $\mathbf{P}$ \\
\hline 11 & Nov. 9, 1956 & $\mathrm{U}$ & 5 & 1.32 & 0.16 & 1.80 & 1.95 & 10.5 & -3.2 & 16.7 & 3.0 & $\mathbf{P}$ \\
\hline 12 & Nov. 10,1956 & $\mathrm{U}$ & 6 & 2.49 & 0.30 & 3.00 & 3.20 & 7.4 & -5.0 & 31.6 & 3.7 & $\mathrm{~S}$ \\
\hline $13^{a}$ & Nov. 12,1956 & $\mathrm{U}$ & 11 & 3.03 & 0.29 & 3.49 & 3.93 & 7.5 & -5.8 & 35.4 & 4.6 & $\mathrm{~S}$ \\
\hline $14^{\mathrm{a}}$ & Nov. 16,1956 & $\mathrm{U}$ & 6 & 2.48 & 0.15 & 2.87 & 3.06 & 6.0 & -4.2 & 40.2 & 4.0 & $\mathrm{~S}$ \\
\hline 15 & Nov. 16,1956 & $\mathrm{U}$ & 7 & 0.63 & 0.14 & 2.06 & 1.66 & 15.2 & -3.0 & 6.3 & 2.4 & $\mathbf{P}$ \\
\hline 16 & Nov. 17,1956 & $\mathrm{U}$ & 8 & 1.39 & 0.24 & 2.04 & 2.04 & 9.6 & -4.4 & 15.7 & 2.8 & $\mathbf{P}$ \\
\hline 17 & Nov. 20,1956 & U & 5 & 1.88 & 0.30 & 2.54 & 2.69 & 10.1 & -6.4 & 20.4 & 3.3 & $\mathbf{P}$ \\
\hline 18 & Nov. 20, 1956 & $\mathrm{U}$ & 4 & 1.38 & 0.06 & 1.92 & 2.02 & 12.4 & -6.4 & 18.1 & 3.2 & $\mathbf{P}$ \\
\hline 19 & Nov. 21, 1956 & $\mathbf{U}$ & 7 & 0.98 & 0.15 & 2.09 & 2.11 & 16.0 & -6.7 & 8.9 & 2.9 & $\mathbf{P}$ \\
\hline 20 & Dec. 24,1955 & $\mathrm{U}$ & 4 & 1.29 & 0.28 & 2.13 & & 11.8 & -3.6 & 12.7 & & $\mathrm{~S}$ \\
\hline 21 & Dec. 25,1955 & $\mathrm{U}$ & 3 & 1.30 & 0.30 & 1.85 & & 12.4 & -3.2 & 17.8 & . & $\mathrm{s}$ \\
\hline 22 & Dec. 28,1955 & U & 12 & 1.72 & 0.17 & 218 & & 9.3 & -3.8 & 16.5 & & $\mathrm{~S}$ \\
\hline 23 & Jan. 3, 1956 & $\mathrm{U}$ & 6 & 2.15 & 0.30 & 2.63 & $\cdots$ & 8.3 & -4.8 & 28.9 & . & $\mathrm{S}$ \\
\hline 24 & Jan. 4, 1956 & $\mathrm{U}$ & 6 & 2.47 & 0.36 & 2.99 & & 8.4 & -5.5 & 30.5 & & $\mathrm{~s}$ \\
\hline 25 & Jan. 11, 1956 & $\mathrm{U}$ & 5 & 1.41 & 0.20 & 1.67 & & 7.4 & -2.7 & 36.8 & & $\mathrm{~S}$ \\
\hline 26 & Oct. 31, 1956 & D & 5 & 1.95 & 0.62 & 3.20 & 3.31 & 10.4 & -4.2 & 17.2 & 3.1 & $\mathbf{P}$ \\
\hline 27 & Nov. 1,1956 & D & 5 & 1.73 & 0.63 & 2.33 & 2.61 & 10.0 & -3.0 & 18.5 & 3.5 & $\mathbf{P}$ \\
\hline 28 & Nov. 2,1956 & D & 4 & 1.27 & 0.35 & 1.72 & 2.17 & 8.9 & -2.8 & 20.0 & 5.2 & $\mathbf{P}$ \\
\hline 29 & Nov. 3, 1956 & D & 7 & 1.39 & 0.17 & 1.83 & 2.10 & 8.3 & -2.4 & 20.8 & 3.7 & $\mathbf{P}$ \\
\hline 30 & Nov. 5,1956 & D & 3 & 2.74 & 0.12 & 3.54 & 3.86 & 7.6 & -3.6 & 23.4 & 3.7 & $\mathbf{P}$ \\
\hline 31 & Nov. 6,1956 & D & 3 & 2.33 & 0.59 & 2.98 & 3.25 & 8.0 & -4.6 & 24.1 & 3.7 & $\mathbf{P}$ \\
\hline 32 & Nov. 6,1956 & D & 4 & 1.25 & 0.11 & 3.08 & 2.75 & 13.0 & -3.0 & 7.7 & 2.5 & $\mathbf{P}$ \\
\hline 33 & Nov. 8,1956 & D & 7 & 0.84 & 0.21 & 1.49 & 1.33 & 12.3 & -3.0 & 11.3 & 2.3 & $\mathbf{P}$ \\
\hline 34 & Nov. 9, 1956 & D & 4 & 1.41 & 0.14 & 2.02 & 2.01 & 10.0 & -3.9 & 17.2 & 2.8 & $\mathbf{P}$ \\
\hline 35 & Nov. 16,1956 & D & 3 & 0.50 & 0.19 & 1.63 & 1.32 & 15.2 & -4.0 & 6.3 & 2.4 & $\mathbf{P}$ \\
\hline 36 & Nov. 22,1956 & D & 5 & 0.93 & 0.19 & 2.00 & 2.04 & 17.6 & -7.0 & 8.7 & 2.8 & $\mathbf{P}$ \\
\hline 37 & Nov. 24,1956 & D & 7 & 0.96 & 0.30 & 1.48 & 1.63 & 11.3 & -4.8 & 14.3 & 3.3 & $\mathbf{P}$ \\
\hline 38 & Nov. 26, 1956 & D & 7 & 0.91 & 0.11 & 1.50 & 1.71 & 15.2 & -6.0 & 12.8 & 3.4 & $\mathbf{P}$ \\
\hline
\end{tabular}

a These tests were performed by Lyle Hansen of SIPRE. 
placed in tightly sealed glass containers and allowed to melt. The density of the resulting solution was measured, using hydrometer floats from a salinity kit manufactured by G. M. Manufacturing Co., New York 12, N. Y. All values were corrected to $15^{\circ} \mathrm{C}$, using a table supplied by the manufacturer. The temperature of the beam was measured at two or three levels using Weston dial thermometers inserted into drilled holes. The average temperature of the ice sheet was then determined by using both the results of the dial thermometer measurements and temperatures measured by a series of thermocouples frozen into the ice sheet at $10-\mathrm{cm}$ vertical intervals. Typical temperature and salinity profiles during the period of testing are shown by Anderson and Weeks [1958, Fig 8].

The flexural strength is computed from

$$
\sigma=6 P L / w h^{2}
$$

where $P$ is the force applied to the end of the ice beam at failure; $L$ the distance from the point of application of the force to the point of breakage; w the average width of the ice beam, and $h$ the average thickness of the ice sheet. The results of these tests are presented in Table 1 , and $\sigma$ is plotted against average ice salinity and ice temperature in Figure 1. Each point is the average of all the tests on a given sheet. The push-down

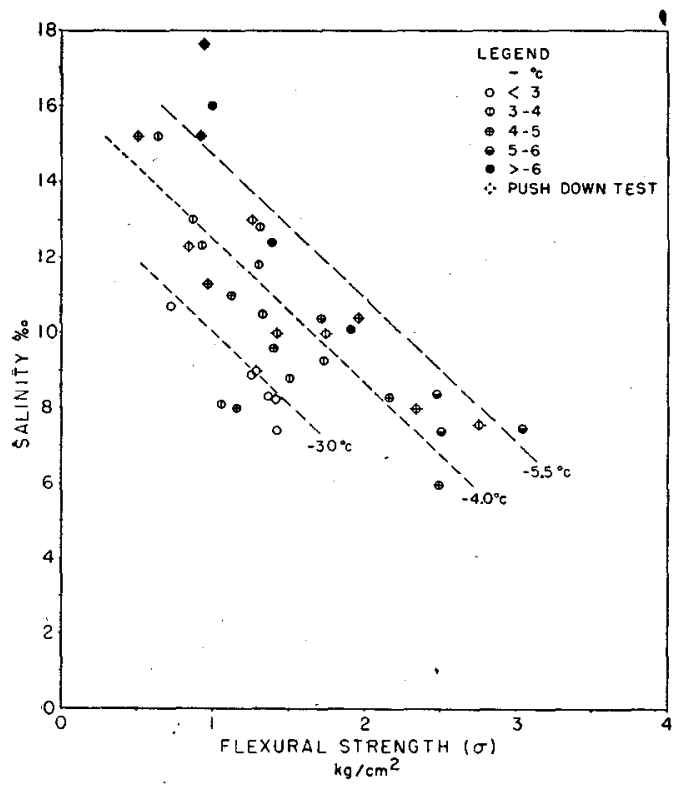

FIG. 1 - Plot of experimental values for flexural strength of sea ice versus salinity at various - temperatures, not allowing for the skeleton layer

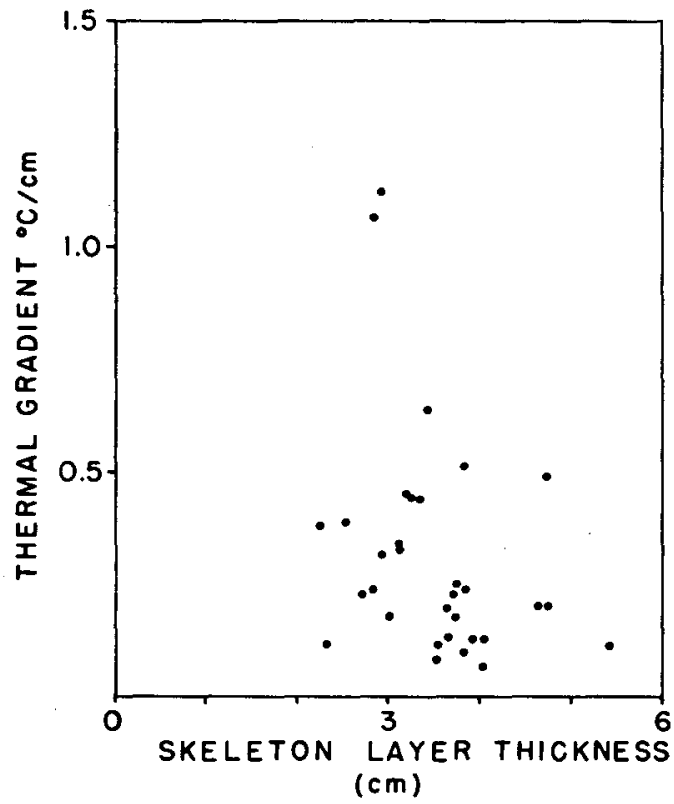

Fig. 2 - Plot of skeleton-layer thickness versus thermal gradient across the ice sheet

tests are identified in the legend. The remainder are pull-ups.

The above formula must be considered as only approximate as applied to sea ice. First, the properties of sea ice vary considerably with depth. A variable section modulus should be used in more accurate work. Secondly, the stress concentration at the butt end of the cantilever has been neglected. This permits our work to be compared directly with that of previous investigators.

The study was undertaken to identify the controlling factors in sea-ice properties and thus relative strengths are studied.

It is surprising that the pull-ups and pushdowns give essentially the same results. The strength of the beam is determined primarily by the strength of the extreme fiber that is in tension. In push-downs this is the cold upper part of the sheet; for pull-ups it is the warm, weak underside. However, we show [Anderson and Weeks, 1958] that the bottom and top are the weaker parts of the ice and the maximum strength exists somewhat above the center of the sheet. The low strength of the top is due to the extremely high salinity which only persists to a very small depth.

At the lower surface of the growing ice sheet there is a strengthless layer of unconnected vertical ice plates which has been referred to by Assur as the skeleton layer [Butkovich, 1956]. The thickness 
of this layer was measured after every test by scraping the underside of the broken cantilever beam with the end of a meter stick until firm ice was reached. In thick, cold sea ice Assur (personal communication) has found that the skeleton layer has a fairly constant thickness varying between 2.4 and $2.8 \mathrm{~cm}$ and that there is a sharp demarcation between it and the overlying ice. In thin, weak sea ice this boundary becomes very vague and apparent skeleton layers of over $5 \mathrm{~cm}$ were measured by the authors. It is felt that these high values are the result of scraping into the overlying ice, which, although too weak to offer appreciable resistance to the meter stick, does have some small strength in tension.

The value of the flexural strength of thin ice is highly dependent upon the proportion of the measured ice thickness that possesses strength. In the case of very thin ice $(<3 \mathrm{~cm})$, essentially the entire ice thickness is composed of the strengthless skeleton layer. This effect, of course, becomes lessened as the ice sheet grows since the skeleton layer remains roughly constant. A number of attempts have been made to relate apparent variations in the skeleton layer to other properties. Figure 2 shows skeleton layer thickness plotted against the thermal gradient in the ice sheet. At the present, however, no definite empirical relation has been established. A theoretical relation has been derived [Anderson and Weeks, 1958].

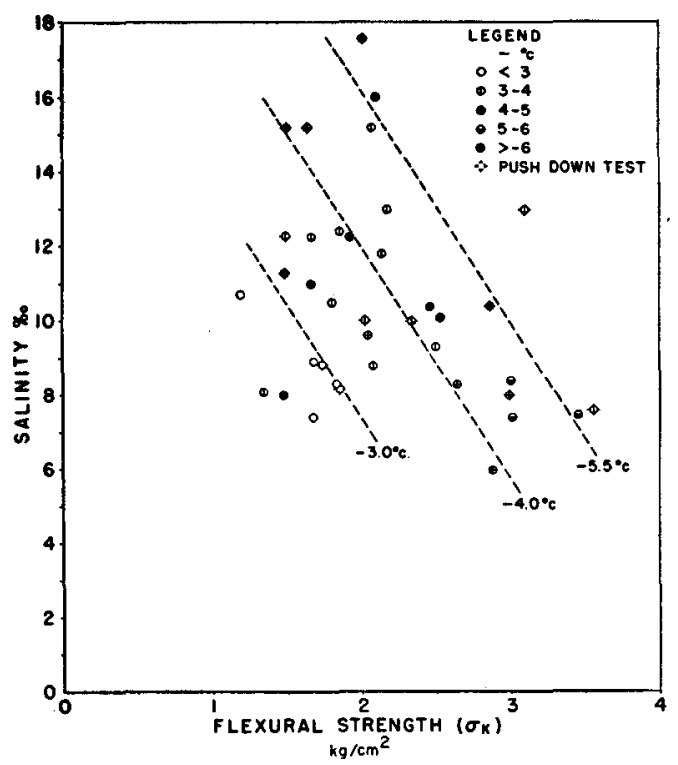

FIG. 3 - Plot of experimental values for flexural strength, assuming a constant $2.8 \mathrm{~cm}$ skeleton layer

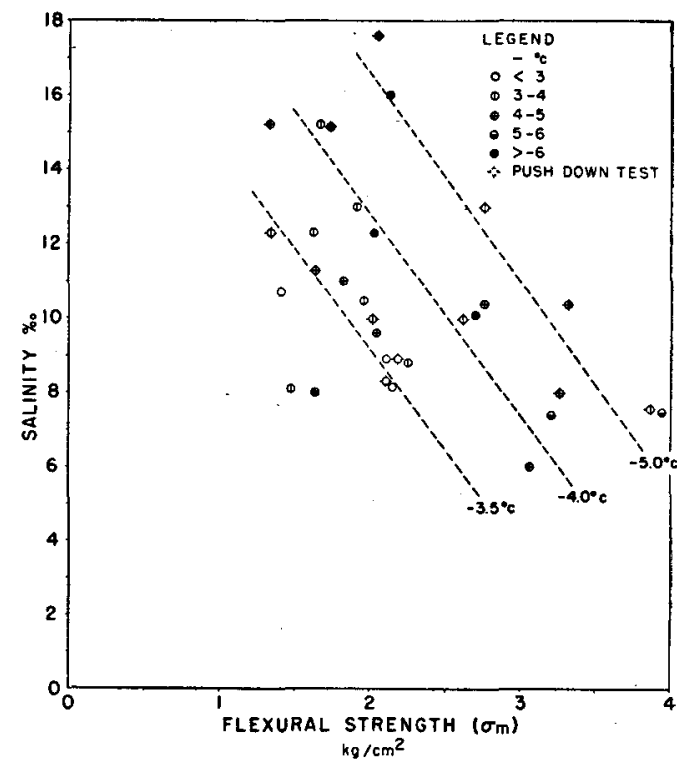

Fig. 4-Plot of experimental values for flexural strength, using the measured skeleton layer

Therefore two other strength values were calculated: $\sigma_{K}$ using for $h$ in (1) the measured ice thickness minus $2.8 \mathrm{~cm}$ (assuming a constant value for the skeleton layer) and $\sigma_{M}$ using the measured ice thickness minus the measured value of the skeleton layer. Figures 3 and 4 show the flexural strengths, $\sigma_{K}$ and $\sigma_{M}$, plotted against average ice salinity and ice temperature. Again, each point is the average of many tests. The slopes of the isothermal curves were determined by inspection and the exact location of the curves by a method of group averaging.

Since high average salinities $(>14 \%)$ were found only in very thin ice where the skeleton layer makes up an appreciable portion of the thickness of the ice sheet, the isothermal lines in Figure 1 have a much less negative slope than the lines in Figures 3 and 4.

In comparing strength values from the in-place beam tests with results from small sample tests, either $\sigma_{K}$ or $\sigma_{M}$ should be used since the skeleton layer is always removed in preparing ice specimens for small sample testing. These values must also be used in calculating the bearing capacity of sea ice, since the uncorrected flexural strength $\sigma$ applies only to the specific ice conditions at the time of testing, that is, portion of the ice sheet that is skeleton layer.

Young's modulus-For the measurement of Young's modulus on in-place samples of young 
sea ice, a semi-infinite beam test developed by A. Assur of SIPRE was used. The test procedure is as follows: a $30-\mathrm{cm} \times 16-\mathrm{m}$ semi-infinite ice beam is cut in the ice sheet. A force is then applied to the free end of the beam causing the beam to break at a distance $L$ from the position of the applied force. The process is then repeated at the new end of the beam. After a number of segments are broken off, the average length of each segment, the thickness of the ice and skeleton layer, and its salinity and temperature profiles are measured.

It can be shown [Hetényi, 1946] that for a semiinfinite beam on an elastic foundation

$$
M=-(P / \lambda) e^{-\lambda l} \sin \lambda l
$$

where $M$ is the bending moment, $P$ the vertical force applied to the end of the beam, $l$ any distance from the end of the beam, and $\lambda$ the characteristic of the system defined as

$$
\lambda \equiv \sqrt[4]{w K / 4 E I}
$$

where $w$ is the width of the beam, $K$ the foundation modulus (in this case equal to the density of sea water of $\sim 32 \%$ salinity at its freezing point, which is $\sim 1.0 \mathrm{~g} / \mathrm{cm}^{3}$ ); $E$ is Young's modulus (the Young's modulus determined by this test is definitely not a reversible process where the sample returns to its initial dimension after testing); and $I$ is the moment of inertia $w h^{3} / 12$, where $h$ is the thickness of the beam. This is only approximate since the beam is not homogeneous throughout its thickness. This semi-infinite beam will break at the position where the bending moment $M$ is at a maximum. Therefore

$$
d M / d l=-P e^{-\lambda l}(\cos \lambda l-\sin \lambda)
$$

which goes to zero at consecutive values of $\lambda l=$ $\pi / 4,5 \pi / 4$, etc. Substituting for $\lambda$ we obtain

$$
\sqrt[4]{3 K / E h^{3}}=\pi / 4 l
$$

But since $K=\cong 1.0 \mathrm{~g} / \mathrm{cm}^{3}$

$$
E=7.88 L^{4} / h^{3}
$$

where $L$ and $h$ are in $\mathrm{cm}$ and $E$ is in $\mathrm{g} / \mathrm{cm}^{2}$.

In performing these tests care had to be taken to prevent friction between the sides of the semiinfinite beam and the ice sheet. The length of the beam was kept $>(1.5 \pi) / \lambda$. If the effective length of the beam is less than this value, the beam can no longer be considered as semi-infinite.

The results of these tests are presented in Figure 5. A large scatter in the values is evident. There is no obvious relation between Young's modulus and the ice temperature and salinity. This result is rather surprising since other properties of sea ice are definitely a function of the brine content. The lack of a relation between these properties is obviously caused by the large scatter in the experimental values and insufficient data. Owing to the nature of the test procedure, it is difficult to determine the values of $E_{K}$ or $E_{M}$ (the subscripts have the same meaning as in the preceding section) with accuracy, since Young's modulus is inversely proportional to the cube of the effective thickness

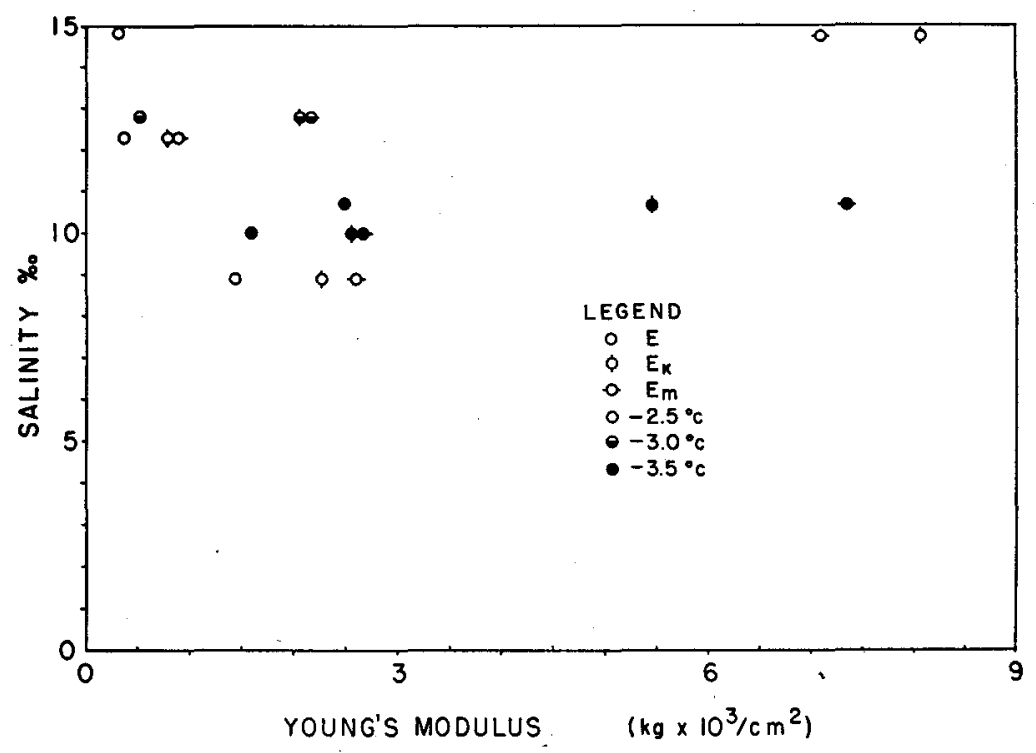

FIG. 5 - Plot of Young's modulus as determined from semi-infinite beam tests 


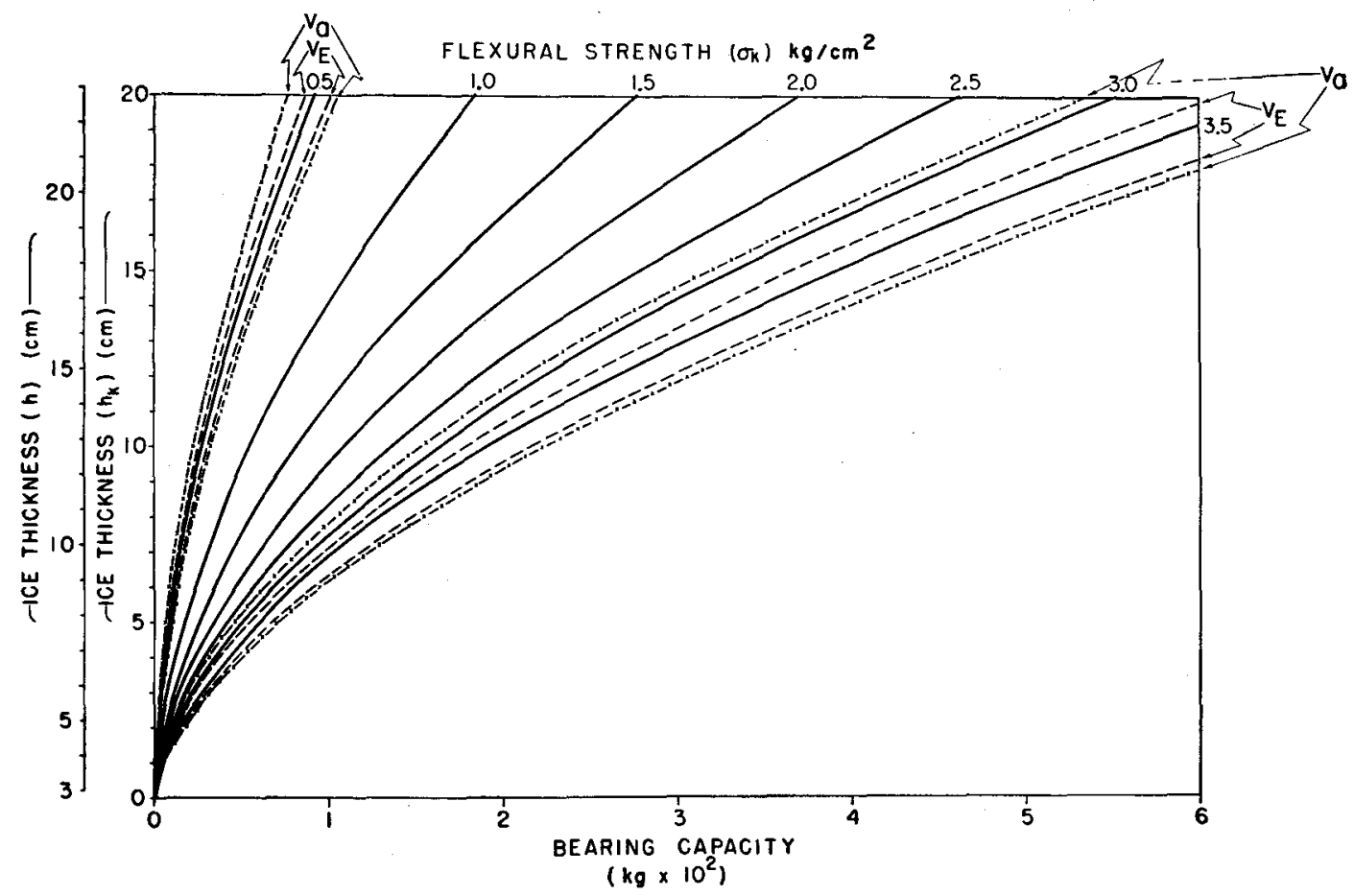

FIG. 6 - Curves showing relationship between bearing strength of a sea-ice sheet and thickness at various values of flexural strength and showing the effect of changing the load radius and changing Young's modulus

of the ice sheet, the value of which, as discussed earlier, depends on an exact measurement of the thickness of the skeleton layer. There is however general agreement between the values for $E_{K}$ and $E_{M}$ which average 3570 and $3800 \mathrm{~kg} / \mathrm{cm}^{2}$ and values determined graphically from the slopes of small sample stress-strain curves by Butkovich [1956] on much colder ice. His values varied from 4520 to $10,225 \mathrm{~kg} / \mathrm{cm}^{2}$ in the temperature range of -4.9 to $-18^{\circ} \mathrm{C}$.

Bearing capacity - It is interesting to use the experimentally determined values of $\sigma_{K}$ and $E_{K}$ to calculate the ice thickness required to support a walking man and other light loads. This can be done using an analysis developed by Hertz [1884] and Wyman [1950]. Considering the sheet of thin ice as an infinite isotropic elastic plate resting on an elastic foundation, the force $P$ necessary to cause the first crack is given by

$$
P=\frac{\pi \sigma_{K} b h^{2}}{3(l+\gamma) k e i^{\prime} b}
$$

where $\gamma$ is Poisson's ratio, $k e i^{\prime} b=(0.6159-$ $\ln b)(b / 2)+\pi b^{3} / 64+\cdots[M c$ Lachlan, 1941] and $b=a / l_{1}$ where $a$ is the radius of the circular loading and $l_{1}$ is the so-called radius of relative stiffness defined by

$$
l_{1}=\sqrt[4]{\bar{D} / K}
$$

where $K$ is the foundation modulus and $D$ the flexural rigidity

$$
D=E_{K} h^{3} / 12\left(1-\gamma^{2}\right)
$$

Figure 6 shows the bearing capacity at the first crack plotted against the measured ice thickness $h$, the effective ice thickness $h_{K}$, and the flexural strength $\sigma_{K}$. The values used in calculating these curves are $E_{K}=3570 \mathrm{~kg} / \mathrm{cm}^{2}, a=15 \mathrm{~cm}, \gamma=$ 0.36 , and $K=10^{-3} \mathrm{~kg} / \mathrm{cm}^{3}$. The change in the position of the $\sigma_{K}=0.5$ and $3.5 \mathrm{~kg} / \mathrm{cm}^{2}$ curves are shown for the values of $E_{K}=1000$ and 8000 $\mathrm{kg} / \mathrm{cm}^{2}$ (the maximum variation in the measured values) and $a=7.5$ and $22.5 \mathrm{~cm}$. As can be seen there is less variation $\left(V_{E}\right)$ in the bearing capacity from a reasonable change in magnitude of $E_{\boldsymbol{K}}$ than from a reasonable change $V_{a}$ in $a$. Therefore even though the Young's modulus tests discussed earlier in this paper did not give a precise determination of $E_{\bar{K}}$, the measured values can be used to calculate the bearing capacity of an ice sheet without introducing an appreciable error.

It is interesting to compare the calculated 
bearing strengths with observations made during the Thule freeze-up. One of the authors (DLA) was trapped on the off-shore side of a newly frozen lead of a width of $\sim 15 \mathrm{~m}$. As he crossed the lead, using a rapid shuffle, an extreme deflection was noted in the ice sheet and a series of large waves was observed in the ice. When he paused to study the deflection dish around him, a soft crackling sound and a rapid sagging were noted. The ice in the center of the lead was $8 \mathrm{~cm}$ thick. Two days later the authors repeatedly crossed over ice areas of $10 \mathrm{~cm}$ in thickness, and, although a noticeable deflection was observed, there was no evidence of breakthrough even after jumping on the ice. The weights of the persons in these instances was $\sim 90 \mathrm{~kg}$ and $\sigma_{K}$ was estimated to be $\leq 1.5 \mathrm{~kg} / \mathrm{cm}^{2}$. From Figure 6 it can be seen that when the ice thickness was $8 \mathrm{~cm}$ the ice was loaded far beyond the first crack. Upon stopping, the man probably would have broken through the ice in a short period of time. With $10 \mathrm{~cm}$ of ice, however, even though the ice sheet was loaded slightly beyond the first crack, it was able to support the load for an appreciable length of time without noticeable signs of failure. This conclusion is in agreement with studies of A. Assur (personal communication), who has shown by comparing field tests with theoretical computations that ice sheets are capable of supporting a large 'super load' beyond the force necessary to form the first crack.

\section{REFERENCES}

ANDERson, D. L., AND W. F. WeEks, A theoretical analysis of sea ice strength, Trans. Amer. Geophys. Union, 39, 632-640, 1958.
BUTKovIch, T. R., Strength studies of sea ice, SIPRE Research Paper 20, 15 pp., 1956.

HeTÉNyI, M., Beams on elastic foundations, Univ. Michigan Press, Ann Arbor, 255 pp., 1946.

Hertz, H., Ueber das Gleichgewicht schwimmender elastischer Platten, Wiedmann's Annalen der Phys. Chem., 22, 449-455, 1884.

MaLmgren, F., On the properties of sea ice, Sci. Res. Norvegian North Pole Exped. with the Maud, 19181925, 1 (5), 67 pp., 1927.

McLachlan, N. W., Bessell functions for engineers, Oxford Univ. Press, London, 192 pp., 1941.

Neronov, I. U. N., The problems of the value of temporary resistance of thawing spring ice to bending, in Data on the problem of ice crossings, ed. by B. L. Lagutin, Trudy Nauchno-Issledovatel'skikk Uchrezhdeniz, Seriya 5, Vyp. 20, 1946 (trans. by Arctic Constr. and Frost Eff. Lab., pp. 64-69, 1954).

Perrov, I. G., Physical-mechanical properties and thickness of the ice cover, Observational data of the Scientific-Research Drifting Station of 1950-51, ed. by M. M. Somov, Leningrad, Izd. 'Morskoi 'Transport,' pp. 1-42, 1955 (trans. by Amer. Met. Soc., 2(6), 60 pp. +42 tables, 1957).

VEINBERG, B. P., Led: svoistva, vozniknovenie $i$ ischesznovenie l'da, (Ice, its properties, origin, and disappearance), Gosizdat tekhnikoteoreticheskoi literatury, Moscow, 1940.

Wyman, M., Deflections of an infinite plate, Canadian J. Res., 28A, 293-302, 1950.

Department of Geology, Washington University, St. Louis 5, Missouri (W. F.W.) and Geophysics Research Directorate, Air Force Cambridge Research Center, Bedford, Massachusetts (D. L. A.).

(Communicated manuscript received September 5, 1957; open for formal discussion until January 1, 1959.) 